Bond University

Research Repository

\title{
A performance analysis of a Stand Up Paddle Board marathon race
}

Schram, Ben; Hing, Wayne; Climstein, Michael; Furness, James

Published in:

Journal of Strength and Conditioning Research

DOI:

10.1519/JSC.0000000000001707

Licence:

Unspecified

Link to output in Bond University research repository.

Recommended citation(APA):

Schram, B., Hing, W., Climstein, M., \& Furness, J. (2017). A performance analysis of a Stand Up Paddle Board marathon race. Journal of Strength and Conditioning Research, 31(6), 1552-1556.

https://doi.org/10.1519/JSC.0000000000001707

\section{General rights}

Copyright and moral rights for the publications made accessible in the public portal are retained by the authors and/or other copyright owners and it is a condition of accessing publications that users recognise and abide by the legal requirements associated with these rights.

For more information, or if you believe that this document breaches copyright, please contact the Bond University research repository coordinator. 
1 MANUSCRIPT TITLE: A PERFORMANCE ANALYSIS OF A STAND UP PADDLE

2 BOARD MARATHON RACE

3

4 RUNNING HEAD: A PERFORMANCE ANALYSIS OF SUP

5

6

7

8

9

10

11

12

13

14

15

16

17 
ABSTRACT

19

20

Stand up paddle boarding (SUP) is a rapidly growing sport and recreational activity in which little scientific research exists. A review of the literature failed to identify a single article pertaining to the physiological demands of SUP competition. The purpose of this study was to conduct a performance analysis of a national level SUP marathon race. Ten elite SUP athletes (6 male, 4 female) were recruited from the Stand Up Paddle Surfing Association of Australia to have their race performance in the Australian Titles analyzed. Performance variables included SUP speed, course taken and heart rate, measured with a $15 \mathrm{~Hz}$ GPS unit. Results demonstrated that there was a variation in distance covered (13.3km-13.9km), peak speed $(18.8 \mathrm{~km} / \mathrm{hr}-26.4 \mathrm{~km} / \mathrm{hr})$ and only moderate correlations $(\mathrm{r}=0.38)$ of race result to distance covered. Significantly greater amounts of time were spent in 5-10km/hr speed zones $(\mathrm{p}<0.05)$ during the race. Peak heart rate varied from 168-208bpm amongst the competitors with the average heart rate was $168.6 \pm 9.8 \mathrm{bpm}$. Significantly higher durations were spent in elevated heart rate zones $(\mathrm{p}<0.05)$ with participants spending $89.3 \%$ of their race within 80 100\% of their age-predicted HRmax. Marathon SUP races appear to involve a high aerobic demand, with maintenance of near max heart rates required for the duration of the race. There is a high influence of tactical decisions and extrinsic variables to race results. These results provide a greater understanding of the physiological demands of distance events and may assist in the development of specialised training programs for SUP athletes.

Key words: GPS analysis, water sports, paddle boarding, SUP, Stand Up Paddle. 


\section{INTRODUCTION}

Stand up paddle boarding (SUP) is a new sport, the popularity of which has risen exponentially over the past decade (4). A recent report highlighted that participation in SUP in the United States increased 155\% from the year 2010 to 2014, with the major reason provided for participation being for exercise and to get fit (17). It is a hybrid of surfing and paddling in which participants can either distance paddle and/or surf waves with competitions being held around the world which culminate in an annual world title event sanctioned by the International Surfing Association $(7,13)$. Despite this global popularity, there is currently no scientific literature available regarding the performance aspect of SUP.

The sport involves athletes paddling in a standing position on a board similar to a surfboard however longer ( 8-15ft), thicker (4-8in) and wider (26-31in) than traditional surfboards (14). Propulsion of the board is through a long single-bladed paddle in which the athlete alternates sides ad libitum. The general disciplines of competitive SUP include technical racing, surfing and marathon racing. Technical SUP racing consists of a 4-8km sprint in which participants are limited to a maximum board length of 12'6” (3.81m). Surfing events are held in heats of 20 minutes and 30 minute finals in which the top two scoring waves are counted toward the competitors total (15). Scoring is based upon performing manoeuvers, creating power and speed and getting through closing out sections in a similar manner to traditional surfing. The SUP marathon races, normally over a distance of 20km (12.43miles), allows boards up to 14' with a fixed fin and can be conducted in both open ocean and flat water. Longer races however such as one of the most popular open ocean races, the 'Molokai to Oahu' is a crossing of the Ka'iwi channel in Hawaii a distance of 51.5km (32miles). The Ka'iwi channel of 'channel of bones' as it is know is notorious for its large swells of up to 12 
feet and strong currents (16). It is regarded as the ultimate challenge of physiological endurance and wave riding skills for professional paddlers and water athletes.

As SUP increases in popularity and competitiveness, the importance of testing SUP athletes to provide information for both coaches and athletes increases in parallel. Although the majority of physiological testing of athletes is performed under highly-controlled laboratory conditions, these are often not sport specific conditions $(8,14)$. Endurance athletes commonly use heart rate (HR) monitors as a training tool to monitor exercise intensity and recovery, they are also extremely useful to monitor and to plan training (1). Quantifying movement patterns via global positioning systems (GPS) in sport is also important for coaches and athletes to develop sport specific conditioning programs and to prevent training errors (10).

Research on surfing has identified both internal and external factors which are relevant to surfing performance which may also been applicable to SUP (9). Race results and ultimately race time will depend upon extrinsic variables such as swell (direction and height), currents and wind. Skilled competitors will catch 'bumps' of swell in order to maximise their speed in the open ocean and therefore may choose to alter their line in order to maximise opportunities to catch 'bumps'. Previous research on windsurfing races have shown great variability in total distance covered by competitors (12). It is well known that varying distances can be covered in running marathons when not taking the inside line (point to point strategy) and participants may significantly add additional distance and subsequently extra time to their race. Intrinsic variables can include aerobic and anaerobic fitness of the paddler, balance, stroke rate, length and power output and the racing line chosen by the competitor. As the SUP athlete alternates paddling on each side, the direction of the SUP can be affected while racing and results in 
non-linear movements as the competitor propels themselves forward. Often the side chosen to paddle on is dictated by the extrinsic variables encountered during the event.

Along with the effect of intrinsic and extrinsic variables on SUP marathon races, heart rate intensities during SUP competition are unknown therefore limiting competition preparation and training. The primary aim of this study was therefore to determine the cardiovascular demands of a SUP marathon race and the peak and average speeds attainable during a race.

The secondary aim was to determine differences in distance covered due to extrinsic variables on the day and their influence on race results. This study aims to inform athlete preparation and to assist coaches in planning conditioning and race tactics.

\section{METHODS}

\section{Experimental Approach to the Problem}

To determine the cardiovascular demands of an elite marathon race, a performance analysis measuring peak and average heart rate, peak speed and distance covered was conducted with the use of GPS and HR telemetry. Data was categorised into zones for both heart rate and speeds for the duration of the race to highlight the requirements of this form of competition. To ascertain the effect of the extrinsic variables on the day (swell, currents and wind) total distance covered was correlated to race result.

\section{Subjects}

A total of ten elite (6 male, 4 female) ranked SUP participants (34.78 $\pm 11.49 y$ yrs) recruited from the Stand Up Paddle Surfers Australia volunteered to participate in this study. SUP participants were competing in the Australian titles in the marathon distance event as a qualifying event for the Australian team for the world championships. The participants were 
all currently ranked nationally or internationally with all participants being ranked in the national top 10 or international top 24. Each participant was informed of the benefits and risks of the investigation and signed an intuitionally approved informed consent document prior to participation in this study. This study was approved by the University Human Research Ethics Committee (RO-1550).

\section{Procedures}

Each participant was familiarised with the GPS device and instructed where to place both the heart rate strap and GPS receiver unit (GPSports HPISPU, $15 \mathrm{~Hz}$, dimensions $=74 \mathrm{~mm} \mathrm{x}$ $42 \mathrm{~mm} \times 16 \mathrm{~mm}$, weight $=67 \mathrm{grams})$. The heart rate straps $(\mathrm{T} 34$ transmitter, $5 \mathrm{kHz}$, Polar, Finland) were placed around the participant's chest and the GPS units were placed in a water proof zip-lock bag on the front or back pocket of the participant's hydration packs worn on the chest. The point to point distance of the SUP marathon event was $12.7 \mathrm{~km}$ (7.89miles) and the course headed in a southerly direction to an inlet $11.3 \mathrm{~km}$ (7.02miles) away with a subsequent $1.4 \mathrm{~km}$ (0.87miles) paddle through a river mouth and into the river in a 'westerly' direction.

The environmental conditions on the day involved a $0.89 \mathrm{~m}$ low tide, 11 knot average northerly wind with 14 knot gusts, $0.5 \mathrm{~m}$ of ENE swell with a 5 sec wave period at the beginning of the race. All GPS units were activated 10 minutes prior to the start of the event to ensure they linked up with the required number of satellites ( $\mathrm{n}>3$ ). Following completion of the event, raw data was downloaded using specialised software (GPSports: Team AMS Release R1) and the pre and post-event periods were eliminated from data analysis. 


\section{Statistical Analyses}

141 Descriptive statistics were used to determine means, ranges and standard deviations of each

142 of the results obtained. A Pearson correlation analysis between distance covered and race

143 result was also performed. Normality was assessed via Shapiro-Wilk $(\mathrm{p}<0.05)$. Data which

144 was not normally distributed was assessed using a Friedman Test with a Wilcoxon Signed

145 Ranks test post hoc. All data analysis was conducted using Statistical Package for the Social

146 Sciences (SPSS, version 20.0, Armonk, NY, USA).

\section{RESULTS}

Nine out of the ten participants finished the race with one participant having to withdraw due to minor injury (muscle strain). Their individual course plots are shown in Figure 1, where at the widest point while in the open ocean, participants were spread 660m apart from one another.

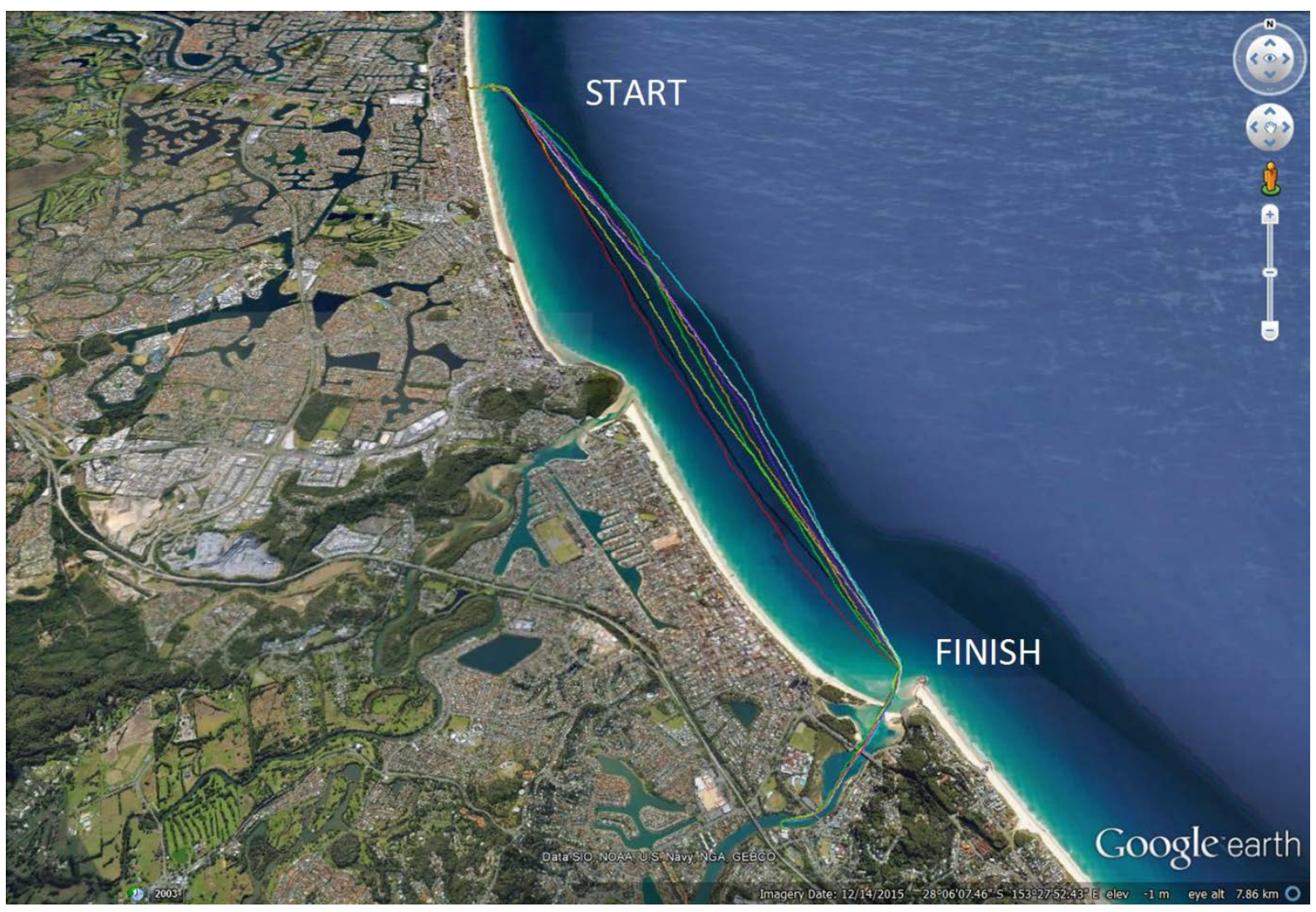


155 As seen in Table 1, athletes spent $89.31 \%$ of their race within $80-100 \%$ of their age predicted HRmax (220-age) and spent a significantly higher $\left(\chi^{2}(4)=25.36, p<0.001\right)$ amount of time in zone 3 (80-90\% of HRmax) and zone 4 (90-100\% of HR max) than the other zones. There was a significant difference in duration spent in speed zones $\left(\chi^{2}(4)=33.69, p<0.001\right)$ with significantly more time spent in the $5-10 \mathrm{~km} / \mathrm{hr}$ zone $(\mathrm{Z}=-2.666, \mathrm{p}=0.011)$. Incremental increases in cardiovascular demand as seen by elevation of heart rate were seen from the start of the race with maintenance of $80-100 \%$ of the participants HRmax for the duration of the race. Speed is seen to be more variable with peak speed being at the point when participants were paddling in a westerly direction, enabling them to ride waves.

Table 1: Time spent in velocity and heart rate zones for the race. Values presented are mean \pm SD.

\begin{tabular}{|c|c|c|c|c|c|}
\hline & Velocity (km/hr) & Time (s) & Time (\%) & $\%$ HR Max & \% of race \\
\hline Zone 1 & $0-5$ & $46.48 \pm 36.58 \times *$ & $0.90 \pm 0.59 \%$ & $60-70 \%$ & $4.84 \pm 7.60 \% * \dagger$ \\
\hline Zone 2 & $5-10$ & $3353.83 \pm 958.36^{*}$ & $66.06 \pm 13.03 \%$ & $70-80 \%$ & $3.95 \pm 4.38 \% * \dagger$ \\
\hline Zone 3 & $10-15$ & $1567.12 \pm 527.09 \times$ & $32.30 \pm 12.89 \%$ & $80-90 \%$ & $27.46 \pm 34.02 \%$ \\
\hline Zone 4 & $15-20$ & $34.03 \pm 21.94 \times *$ & $0.71 \pm 0.50 \%$ & $90-100 \%$ & $61.85 \pm 32.12 \%$ \\
\hline Zone 5 & $>20$ & $1.38 \pm 1.89^{\times *++}$ & $0.03 \pm 0.04 \%$ & $>100 \%$ & $1.09 \pm 4.50 \% * \dagger$ \\
\hline & Total & $5002.95 \pm 447.86$ & $100 \%$ & Total & $100 \%$ \\
\hline
\end{tabular}

$+=$ significantly less than zone $1, \times=$ significantly less than zone $2, *$ = significantly less than zone 3 $\mathrm{p}<0.05, \uparrow=$ significantly less than zone $4 \mathrm{p}<0.05$ )

The group, male and female averages displayed in Table 2 shows that participants covered an average distance of $13.56 \mathrm{~km}$ with a range of $13.34 \mathrm{~km}$ to $13.87 \mathrm{~km}$. Time to completion varied from 1:15.1 to 1:39.9. Peak heart rate recorded ranged from 168bpm (98\%HRmax) to 208bpm (103\%HRmax). Peak speeds recording during the event was $26.39 \mathrm{~km} / \mathrm{hr}$ by the winning female and the highest average speed recorded being $10.8 \mathrm{~km} / \mathrm{hr}(3.0 \mathrm{~m} / \mathrm{s})$ from the 
winning male. There was a moderate, positive correlation between the participant's distance covered and their race results. This relationship was not significant $(\mathrm{p}=0.385)$.

Table 2: Participant demographics and GPS results. Values presented are mean $( \pm$ SD)

\begin{tabular}{|c|c|c|c|}
\hline Parameter & Group $(n=9)$ & Males $(n=6)$ & Females $(n=3)$ \\
\hline Age (yrs) & $34.78 \pm 11.49$ & $31.11 \pm 12.32$ & $41.67 \pm 6.43$ \\
\hline Height (cm) & $172.14 \pm 7.50$ & $176.38 \pm 4.55$ & $163.67 \pm 3.51$ \\
\hline Weight (kg) & $72.03 \pm 10.13$ & $77.67 \pm 6.85$ & $60.77 \pm 2.70$ \\
\hline BMI $\left(\mathrm{kg} / \mathrm{m}^{2}\right)$ & $24.17 \pm 2.55$ & $24.88 \pm 2.70$ & $22.73 \pm 1.79$ \\
\hline Years Competition (yrs) & $5.39 \pm 1.65$ & $5.08 \pm 1.91$ & $6.00 \pm 1.00$ \\
\hline Ranking & $\begin{array}{c}\text { 5-24 International } \\
\text { 2-10 National }\end{array}$ & $\begin{array}{c}\text { 5-24 International } \\
\text { 5-10 National }\end{array}$ & $\begin{array}{c}\text { 6-24 International } \\
\text { 2-5 National }\end{array}$ \\
\hline Course completion time (min) & $83.37 \pm 7.47$ & $79.87 \pm 4.10$ & $90.40 \pm 8.37$ \\
\hline Course distance covered (m) & $13564.65 \pm 157.05$ & $13508.97 \pm 128.44$ & $13676.02 \pm 171.76$ \\
\hline Peak speed (m/s) & $21.27 \pm 0.70$ & $20.95 \pm 2.24$ & $21.90 \pm 3.91$ \\
\hline Average speed (m/s) & $9.78 \pm 0.70$ & $10.13 \pm 0.53$ & $9.07 \pm 0.41$ \\
\hline Distance per minute (m) & $163.21 \pm 12.68$ & $169 \pm 9.19$ & $151.63 \pm 11.43$ \\
\hline Average heart rate (bpm) & $168.56 \pm 9.79$ & $172.00 \pm 10.32$ & $161.67 \pm 3.21$ \\
\hline Peak heart rate (bpm) & $187.00 \pm 13.52$ & $194.17 \pm 9.87$ & $172.67 \pm 5.03$ \\
\hline
\end{tabular}

\section{DISCUSSION}

Previously, no scientific literature was available on the physiological (HR) demands and time motional analysis of a marathon SUP event. This study aimed to provide an understanding of the requirements of such a race and how extrinsic variables may influence race results and tactics. The majority of times, participants were in steady state with regard to speed and HR however peak speed occurred when the participant was paddling toward shore and when catching open ocean swell lines, the latter being highly advantageous to achieving a shorter race time. 
189 The heart rates were variable in this race partly due to the variation in ages (18-55yrs). The

190 national competition is divided into open men's and women's, over 40's and over 50's.

191 Although age limits maximum heart rate, all athletes were able to maintain their heart rates

192 above $150 \mathrm{bpm}$ for the duration of the race. The lowest heart rates were seen at the beginning

193 of the race where they increased rapidly and were maintained for the majority of the race at

$19480-100 \%$ of their HRmax. Participants spending almost $90 \%$ of the race within $80-100 \%$ of

195 their age predicted HRmax comparable to previous research in windsurfing with participants

196 required to maintain between $87.4 \%$ to $92 \%$ of HRmax for the duration of their events (2, 3).

197 Road cyclists have been reported to maintain heart rates of 80-89\% of HRmax during time

198 trials over 10-50km(11) and 84.1-90\% HRmax in mountain biking (5, 6).

The low correlation ( $r=0.384)$ between the distance covered by SUP participants and the race results demonstrated that SUP race tactics are critical in race results, the shortest distance covered was recorded by a participant who was the seventh across the line. Some of the participants chose a route which was not the shortest distance to the line from a point to point perspective but allowed them to maintain a higher average speed for the duration of the race. The utilisation of tactics may also explain the spread of the field up to 660 meters during this event. The participants finishing in higher places were able to obtain a higher average speed through the duration of the event possibly by regularly catching small waves and utilizing swell lines in the direction of the wind on the day. Although this strategy may result in a SUP participant paddling a greater total distance, the average speed of the participant remained high, therefore ensuring completion of the event in the shortest amount of time. 
This variation in total distance covered due to environmental conditions is similar to what has been previously published in windsurfing events with distances covered having a standard deviation of over $5 \mathrm{~km}$ (12). This is primarily due to the participants seeking out the best extrinsic conditions to maximise their speed across the water. This is most likely the explanation for the variation of over $500 \mathrm{~m}$ in total distance covered between athletes in this race.

There were some limitations in this study. Global positioning analysis of this sport is ideal in populated areas due to accessibility, the ability to closely monitor the athlete and availability of satellites for the GPS units. However, the initial aim of this study was to investigate the Molokai to Oahu challenge in Hawaii. Although initially the 15Hz GPS units worked well, the remoteness of the location resulted in a drop out from satellite coverage. The $15 \mathrm{~Hz}$ units, despite being more accurate, require a greater number of satellites to be able to log data. It is suggested for future studies; researchers ensure adequate satellite coverage in the location of the SUP events.

\section{PRACTICAL APPLICATIONS}

This study provides athletes and coaches with data on the physiological requirements of marathon SUP events and highlights the importance of race tactics. Marathon SUP events require near maximal heart rates for the duration of the race, meaning a high aerobic capacity is required for success in this format. Training intensities therefore need to replicate this high aerobic demand. Coaches and athletes need to acknowledge the effect that extrinsic variables during a race will have on optimum course selection, race speeds and consequently the shortest race times. It could be suggested that athletes arrive early to competition locations in order to adequately prepare for the local conditions (winds, tides, currents, swell). These 
findings are applicable for both SUP athletes and coaches to assist with sports specific

training sessions and understand the influence of race tactics on overall results.

\section{REFERENCES}

1. Achten J and Jeukendrup AE. Heart Rate Monitoring: Applications and Limitations. Sports Medicine 33: 517-517, 2003.

2. De Vito G, Di Filippo L, Rodio A, Felici F, De Vito A, and Madaffari A. Is the Olympic boardsailor an endurance athlete? Int J Sports Med 18: 281-284, 1997.

3. Guével A, Maïsetti O, Prou E, Marini JF, and Dubois JJ. Heart rate and blood lactate responses during competitive Olympic boardsailing. J Sports Sci 17: 135-141, 1999.

4. Hammer S. Catch the wave of stand up paddling. The Providence Journal Sep 5: 3, 2011.

5. Herrick JE, Flohr JA, Wenos DL, and Saunders MJ. Comparison of physiological responses and performance between mountain bicycles with differing suspension systems. Int J Sports Physiol Perform 6: 546, 2011.

6. Impellizzeri FM and Marcora SM. The physiology of mountain biking. Sports medicine (Auckland, NZ) 37: 59-71, 2007.

7. http://www.isasurf.org/. Accessed 26 July/2012.

8. Larsson P. Global Positioning System and Sport-Specific Testing. Sports medicine (Auckland, NZ) 33: 1093-1093, 2003.

9. $\quad$ Mendez-Villaneuva A and Bishop D. Physiological Aspects of Surfboard Riding Performance. Sports medicine (Auckland, NZ) 35: 55-70, 2005.

10. Munoz I, Cejuela R, Seiler S, Larumbe E, and Esteve-Lanao J. Training-Intensity Distribution During an Ironman Season: Relationship With Competition Performance. Int J Sports Physiol Perform 9: 332-339, 2014.

11. Padilla S, Mujika I, Orbañanos J, and Angulo F. Exercise intensity during competition time trials in professional road cycling. Med Sci Sports Exerc 32: 850, 2000.

12. Perez-Turpin JA, Cortell-Tormo JM, Suarez-Llorca C, Andreu-Cabrera E, Llana-Belloch S, and Perez-Soriano P. Relationship Between Anthropometric Parameters, Physiological Responses, Routes and Competition Results in Formula Windsurfing. AKUT 14: 95-112, 2009.

13. Schram B, Hing W, and Climstein M. Laboratory-and field-based assessment of maximal aerobic power of elite stand-up paddle-board athletes. Int J Sports Physiol Perform 11: 28-32, 2016.

14. Schram B, Hing W, and Climstein M. Profiling the sport of stand-up paddle boarding. J Sports Sci 34: 937-944, 2016.

15. http://www.sup-australia.com/events/rules-sup-surfing. Accessed 26/08/2012.

16. http://sup.surftech.com/2012/07/27/who-to-watch-molokai-2-oahu-2012/. Accessed $07 / 08 / 12 /$.

17. The Outdoor Foundation. 2015 Special Report on Paddlesports. Washington, 2015. 
ACKNOWLEDGEMENTS

281 The authors wish to thank Troy Pease from AUSUP and all the competitors who agreed to be 282 part of this study during the Australian Titles Competition. 